Pesq. Vet. Bras. 37(12):1369-1372, dezembro 2017 DOI: $10.1590 / \mathrm{S} 0100-736 \mathrm{X} 2017001200002$

\title{
Surto de botulismo tipo C em equinos no Rio Grande do Sul ${ }^{1}$
}

\author{
Fernando F. Argenta ${ }^{2}$, Guilherme Konradt ${ }^{2}$, Daniele M. Bassuino ${ }^{2}$, Rafaela A. Caprioli ${ }^{2}$, \\ Cláudio J.M. Laisse ${ }^{2}$, Ana Carolina Borsanelli ${ }^{3}$, Iveraldo S. Dutra ${ }^{3}$ e David Driemeier ${ }^{2 *}$
}

\begin{abstract}
Argenta F.F., Konradt G., Bassuino D.M., Caprioli R.A., Laisse C.J.M., Borsanelli A.C., Dutra I.S. \& Driemeier D. 2017. [Outbreak of type C botulism in horses in Rio Grande do Sul.] Surto de botulismo tipo C em equinos no Rio Grande do Sul. Pesquisa Veterinária Brasileira 37(12):1369-1372. Setor de Patologia Veterinária, Departamento de Patologia Clínica Veterinária, Faculdade de Veterinária, Universidade Federal do Rio Grande do Sul, Av. Bento Gonçalves 9090, Porto Alegre, RS 91540-000, Brazil. E-mail: davetpat@ufrgs.br

Botulism in domestic animals is a fatal poisoning caused by ingestion of Clostridium botulinum neurotoxin. This paper describes epidemiological, clinical and laboratorial aspects of a botulism type C outbreak in horses in a farm in Porto Alegre, Rio Grande do Sul. From a total of 20 horses, seven (35\%) were affected and died, and one was euthanized after presenting poor prognosis. The horses, which were raised extensively, showed similar clinical signs, that included limited mobility, lethargy, progressive flaccid paralysis, muscle tremors, sweating, ataxia, and frequent falls. Four horses were necropsied and did not show significant macroscopic and microscopic lesions. Brain and spinal cord samples were analyzed by direct immunofluorescence and were negative for rabies. Liver fragments from the four necropsied horses, soil sediment samples, and suspect water from two reservoirs were evaluated by direct exam to verify the botulinum toxin and/or Clostridium botulinum spores presence. In the serum neutralization bioassay in mice, the type $\mathrm{C}$ botulinum toxin was detected in one liver sample, at the same time that the soil sediment and water samples were negative in all assays. Based on the epidemiological, clinical and laboratory data the etiological diagnosis of botulism was established by being caused by botulinum toxin type $\mathrm{C}$, and it is suggested that the stagnant water of the dams is the likely source of the toxin.
\end{abstract}

INDEX TERMS: Clostridium botulinum, horses, poisoning, botulism type $\mathrm{C}$, botulinum toxin type C.

RESUMO.- 0 botulismo nos animais domésticos é uma intoxicação fatal ocasionada pela ingestão da neurotoxina de Clostridium botulinum. Este trabalho descreve os aspectos epidemiológicos, clínicos e laboratoriais de um surto de botulismo tipo $\mathrm{C}$ em equinos de uma propriedade rural no município de Porto Alegre, Rio Grande do Sul. Do total de 20 equinos, sete (35\%) foram acometidos e morreram, e um eutanasiado após apresentar prognóstico desfavorável. Os cavalos, criados extensivamente, apresentaram sinais clínicos

\footnotetext{
${ }^{1}$ Recebido em 26 de janeiro de 2016.

Aceito para publicação em 16 de novembro de 2016.

${ }^{2}$ Setor de Patologia Veterinária, Departamento de Patologia Clínica Veterinária, Faculdade de Veterinária, Universidade Federal do Rio Grande do Sul (UFRGS), Av. Bento Gonçalves 9090, Porto Alegre, RS 91540-000, Brasil. *Autor para correspondência: davetpat@ufrgs.br

${ }^{3}$ Departamento de Apoio Produção e Saúde Animal, Faculdade de Medicina Veterinária de Araçatuba, Universidade Estadual Paulista (Unesp), Rua Clóvis Pestana 793, Jardim Dona Amélia, Cx. Postal 533, Aracatuba, SP 16050-680, Brasil. E-mail: isdutra@fmva.unesp.br
}

semelhantes, caracterizados por dificuldade de locomoção, letargia, paralisia flácida progressiva, tremores musculares, sudorese, ataxia e quedas frequentes. Quatro equinos foram necropsiados e não apresentaram lesões macroscópicas e microscópicas significativas. Amostras de encéfalo e medula espinhal foram enviados para realização do exame de imunofluorescência direta e foram negativas para o vírus da raiva. Fragmentos de fígado dos quatro equinos necropsiados, amostras de sedimento do solo e água suspeita de dois açudes da propriedade foram avaliados pelo exame direto para a verificação da presença de toxina botulínica e/ou esporos de Clostridium botulinum. No bioensaio em camundongos e soroneutralização pode-se detectar toxina botulínica tipo C em uma amostra de fígado, ao passo que as amostras de sedimento do solo e água foram negativas em todos os ensaios. Com base nos dados epidemiológicos, clínicos e laboratoriais pode-se estabelecer o diagnóstico etiológico de botulismo causado pela toxina botulínica do tipo C, e sugere-se, a água estagnada dos açudes como aprovável fonte da toxina. 
TERMOS DE INDEXAÇÃO: Clostridium botulinum, equinos, intoxicação, botulismo tipo C, toxina botulínica tipo C.

\section{INTRODUÇÃO}

O botulismo nos animais domésticos é uma intoxicação frequentemente fatal ocasionada pela ingestão da neurotoxina de Clostridium botulinum. A forma esporulada do $C$. botulinum é altamente resistente e prevalente no solo, água estagnada e em matéria orgânica vegetal ou animal. Em ambientes de anaerobiose e em diversos substratos, prolifera-se e produz um dos sete tipos de toxinas (A-G), que se diferenciam de acordo com as suas características estruturais, atividade proteolítica e características antigênicas (Kriek \& Odendaal 2004, Graça et al. 2010). A doença afeta diferentes espécies domésticas e aves silvestres com variação na suscetibilidade quanto aos diferentes tipos de toxina (Valentine \& McGavin 2009). Em equinos, os sorotipos B e C são frequentemente identificados, e ocasionalmente, os sorotipos A e D (Dutra et al. 1993, Johnson et al. 2010). 0 botulismo é uma importante causa de mortalidade na pecuária extensiva e, em bovinos, geralmente está relacionado com a osteofagia (Tokarnia et al. 1970, Döbereiner et al. 1992, Dutra 2001). Surtos associados à ingestão de água contaminada foram descritos em bovinos no Senegal (Doutre 1969, Thiongane et al. 1984) e em búfalos e bovinos no Brasil (Langenegger \& Döbereiner 1988, Dutra et al. 2001). 0 botulismo em pequenos ruminantes e em equinos é considerado raro no Brasil (Fernandes \& Riet-Correa 2007). 0 objetivo deste trabalho é descrever um surto de botulismo tipo C em equinos no Rio Grande do Sul, abordando seus aspectos epidemiológicos, clínicos e laboratoriais.

\section{MATERIAL E MÉTODOS}

Os dados epidemiológicos e clínicos foram obtidos através das visitas à propriedade e pelas informações relatadas pelo proprietário. Em um equino foi realizado exame físico geral e específico do sistema nervoso central de acordo com Riet-Correa et al. (2002). Três cavalos que vieram a óbito e um eutanasiado foram necropsiados e após análise macroscópica, fragmentos de órgãos foram coletados e fixados em formalina a $10 \%$, processados rotineiramente para histologia e corados pela técnica de hematoxilina e eosina (HE). Amostras de encéfalo e medula espinhal foram resfriadas e encaminhadas para exame de imunofluorescência direta (IFD) para vírus da raiva em laboratório oficial. Além disso, fragmentos de fígado, juntamente com amostras de solo do sedimento e água dos açudes da propriedade, mantidos sob refrigeração, foram avaliados para a presença de esporos de $C$. botulinum (amostras de solo e água) ou de toxina botulínica (amostras de fígado e água do açude) pelo teste de bioensaio em camundongo e neutralização pelas antitoxinas botulínicas homólogas, de acordo com a metodologia descrita por Dutra (2001).

\section{RESULTADOS}

\section{Achados epidemiológicos, clínicos e laboratoriais}

Sete equinos, de um total de vinte animais, morreram em um período de quinze dias, em uma propriedade rural localizada no município de Porto Alegre, no Estado do Rio Grande do Sul. Os cavalos eram mantidos exclusivamente sob pastejo em campo nativo de aproximadamente 28 hectares. Segundo o relato do proprietário, dois novos açudes

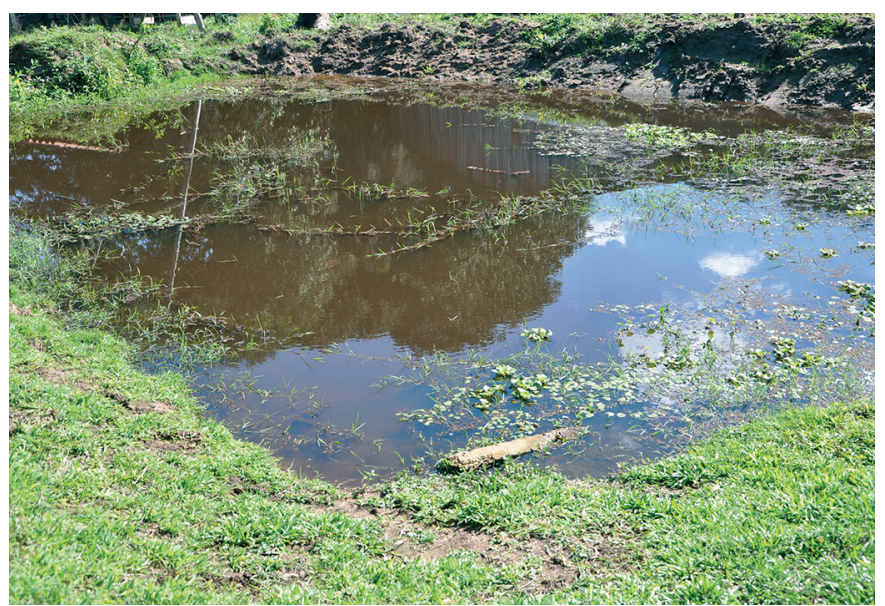

Fig.1. Açude da propriedade onde ocorreu o surto de botulismo tipo $\mathrm{C}$, contendo quantidade rasa de água e matéria orgânica abundante de origem animal e vegetal.

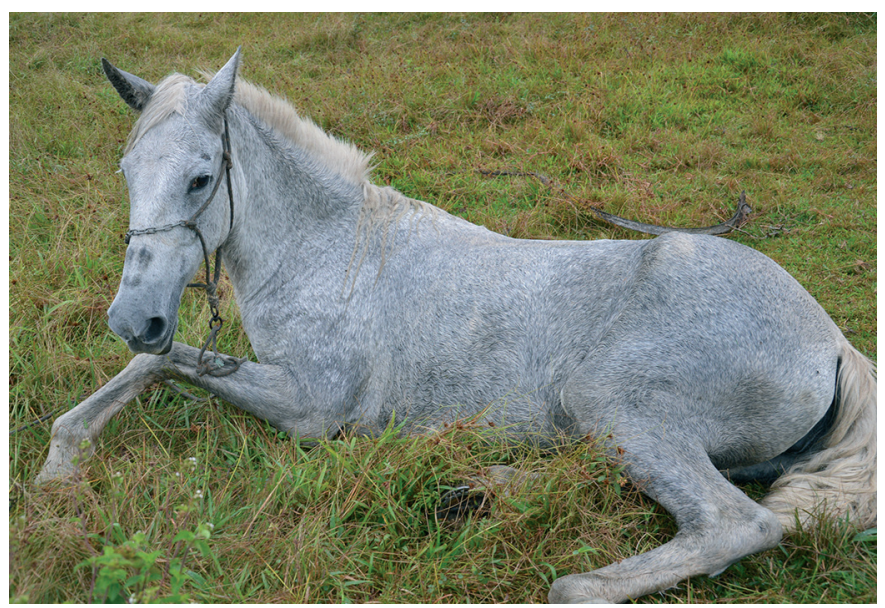

Fig.2. Equino, fêmea, em decúbito esternal e com paralisia de membros pélvicos.

foram abertos e continham quantidade rasa de água e matéria orgânica abundante de origem animal e vegetal (Fig.1). Os equinos afetados tinham idade entre oito a 12 anos, de ambos os sexos, eram everminados e vacinados contra raiva. Segundo o proprietário, todos os cavalos apresentaram sinais clínicos semelhantes, caracterizados por letargia, sudorese, ataxia, quedas frequentes e paralisia de membros pélvicos, sem alteração do apetite, evoluindo para decúbito e morte. Por ocasião da visita, foi realizado exame clínico geral e específico do sistema nervoso de um equino, fêmea, e em bom estado corporal. A égua foi encontrada na propriedade em decúbito esternal (Fig.2) e alimentava-se normalmente, sem dificuldades na apreensão, mastigação e deglutição do pastejo. Quando estimulada, apresentava dificuldade de locomoção e tremores musculares intensos. A realização do exame neurológico foi prejudicada pela gravidade do estado clínico, entretanto foram identificados sinais caracterizados por paraparesia flácida, com hipotonia de cauda, além de diminuição de sensibilidade do panículo e perda do tônus do esfíncter anal. Devido ao quadro clínico desfavorável deste animal, a eutanásia foi realizada. A evolução clínica nos equinos observados variou de 24 a 48 horas. 
Ao exame macroscópico, seguido do histológico de materiais coletados de quatro equinos, não foram observadas lesões significativas. As amostras foram negativas para raiva no exame de IFD.

Em uma amostra de fígado de um dos equinos necropsiados foi detectada pelo bioensaio em camundongo e soroneutralização a toxina botulínica do tipo C. Não foram detectados esporos de C. botulinum nas amostras de sedimento do solo dos açudes; da mesma forma que toxina ou a bactéria nas amostras de água.

\section{DISCUSSÃO}

O diagnóstico de botulismo é realizado primariamente com base no histórico e sinais clínicos, após a exclusão de outras enfermidades neurológicas da lista de diferenciais, e confirmado por testes laboratoriais (Wilkins 2007, Valentine \& McGavin 2009). 0 teste laboratorial de escolha é o bioensaio em camundongos (Wilkins 2007). 0 diagnóstico de botulismo em equinos pela toxina tipo $C$ neste estudo foi baseado nos achados epidemiológicos, clínicos e laboratorial (bioensaio em camundongos). Embora nas amostras de água e do sedimento dos açudes suspeitos não se tenha detectado a presença de esporos de Clostridium botulinum ou de toxina botulínica, a sua detecção em uma amostra de fígado de um dos equinos, associada os sinais clínicos e evolução clínica, corrobora o diagnóstico etiológico. A alta suscetibilidade dos equinos à toxina botulínica (Kriek \& Odendaal 2004) e a complexidade em se detectar a toxina em amostras de água ou alimentos possivelmente contaminados (Dutra 2001, Dutra et al. 2001) auxiliam no entendimento dessa particularidade do botulismo em animais domésticos.

A baixa sensibilidade epidemiológica do bioensaio em camundongo é conhecida no diagnóstico do botulismo em bovinos. Mesmo sendo considerado teste padrão ouro para o diagnóstico do botulismo, pois detecta pelo menos 1 DL50 da toxina quando presente no material suspeito, a sensibilidade da soroneutralização é de $41,3 \%$ quando se emprega amostras de fígado, conteúdo ruminal e intestinal de animais com quadro clínico da doença (Dutra 2001). Nesse contexto, o fato de detectar toxina botulínica em apenas uma amostra de fígado dos equinos necropsiados, sugere-se que esteja relacionado à alta suscetibilidade desta espécie animal, às características da toxina botulínica e às limitações do bioensaio em camundongo.

Além da suscetibilidade dos equinos à toxina botulínica (Valentine \& McGavin 2009), a detecção da toxina botulínica no meio ambiente, assim como de esporos da bactéria, pode ser afetada por fatores, como o local e o momento em que são realizadas as coletas de material, a diluição da toxina em fontes como a água e a baixa sensibilidade do bioensaio em camundongo (Seifert \& Böhnel 1994). Dutra (2001) determinou a sensibilidade do bioensaio em camundongo em $43,1 \%$, quando são examinadas amostras dos animais com sinais clínicos de botulismo.

Equinos podem contrair a doença de três maneiras: por ingestão da toxina pré-formada no alimento (intoxicação da forragem) principalmente em equinos adultos; por ingestão de esporos de C. botulinum tipo B que germinam no trato gastrointestinal e produzem toxinas, principalmente em potros de 1-3 meses de idade (botulismo toxinfeccioso); ou pela contaminação de ferimentos (botulismo de feridas) por esporos de C. botulinum (Whitlock \& McAdans 2006, Wilkins 2007). Sua ocorrência depende de uma série de fatores envolvendo a intensidade da contaminação ambiental, presença de substrato e a existência de condições ideais para a sua multiplicação e formação de toxina. 0 botulismo ocorre, também, após a ingestão de água contaminada com a toxina botulínica (Dutra et al. 2001). No presente trabalho, um importante fator que pôde ter contribuído para a ocorrência destes casos foi a possível contaminação ambiental pelos esporos de $C$. botulinum a partir da abertura de novos açudes e lagoas para represar água em períodos de estiagem. Segundo Ribas et al. (1994) a contaminação ambiental ocorre principalmente a partir de cadáveres que entram em decomposição no campo. Da mesma forma, a existência de valas de captação, utilizadas na dessedentação dos animais, propicia condições ideais à ocorrência de surtos de botulismo hídrico (Barros et al. 2006). Equinos são extremamente sensíveis à toxina botulínica e quando expostos a pequenas quantidades, podem desenvolver a doença (Schoenbaum et al. 2000, Pabilonia 2003). Após a ingestão e absorção intestinal, a toxina bloqueia a transmissão sináptica nas junções neuromusculares, impedindo o estímulo de contração, provocando paralisia flácida generalizada (Graça et al. 2010). Os sinais clínicos desenvolvidos são caracterizados por dificuldade de locomoção, diminuição do tônus da musculatura da língua, disfagia, ataxia dos membros pélvicos e decúbito (Kinde et al. 1991, Schoenbaum et al. 2000, Dutra et al. 2005, Graça et al. 2010). A morte decorre da consequente paralisia da musculatura respiratória (Pabilonia 2003). No presente trabalho, os equinos apresentaram letargia, paraparesia flácida, quedas frequentes evoluindo para decúbito e óbito, sem alteração do apetite. Sinais clínicos semelhantes foram descritos por Ricketts et al. (1984), Kinde et al. (1991) e Ostrowksi et al. (2012), que relataram casos de botulismo na espécie.

Alguns equinos afetados pela doença podem apresentar pneumonia aspirativa causada pela disfagia, além de necrose das miofibras em casos de decúbito prolongado (Valentine \& McGavin 2009), degeneração hepática gordurosa, excesso de líquido no saco pericárdico, além de hemorragias subepicárdicas e subendocárdicas observadas esporadicamente em alguns casos (Kriek \& Odendaal 2004). Kinde et al. (1991), Pabilonia (2003) e Ostrowski et al. (2012), descreveram alguns achados necroscópicos proeminentes, como enterite catarral e hemorrágica e edemas intramusculares multifocais, principalmente na cabeça e pescoço, relatados em surtos de botulismo em equinos na América do Norte; entretanto, se tratam de lesões inespecíficas e nem sempre relacionadas ao botulismo. Nos casos analisados, a apresentação clínica, associada com a ausência de lesões no exame anatomopatológico, corroboram com o descrito por outros autores (Ricketts et al. 1984, Kelly et al. 1984, Schoenbaum et al. 2000).

Dentre os diagnósticos diferenciais de botulismo incluem-se raiva, leucoencefalomalacia, mieloencefalite por protozoário e intoxicação por antibióticos ionóforos (Fer- 
nandes \& Riet-Correa 2007). A raiva é uma enfermidade neurológica com manifestações clínicas variáveis e com lesões histológicas que se caracterizam por uma meningoencefalite e meningomielite não supurativa com gliose multifocal, necrose neuronal e neuroniofagia, afetando encéfalo e, mais frequentemente, medula espinhal em equinos (Bassuino et al. 2016). A meningoencefalite equina por protozoário cursa com sinais clínicos de ataxia e paralisia de membros pélvicos por provocar lesões mais acentuadas em medula espinhal (Vandevelde et al. 2012). A intoxicação por antibióticos ionóforos em equinos leva a um quadro de miopatia necrótica aguda que cursa com ataxia e fraqueza dos membros pélvicos, caracterizados por andar rígido e relutância em se movimentar (Bezerra et al. 2000, Barros 2007). Embora as manifestações clínicas destas enfermidades sejam similares às observadas no botulismo, lesões histopatológicas são caracteristicamente ausentes em casos de botulismo em todas as espécies animais.

\section{REFERÊNCIAS}

Barros C.L.S. 2007. Doenças tóxicas, p.45-49. In: Riet-Correa F., Schild A.L., Lemos R.A.A. \& Borges J.R.J. (Eds), Doenças de Ruminantes e Equídeos. Vol.1. 3a ed. Pallotti, Santa Maria. 691p.

Barros C.L.S., Driemeier D., Dutra I.S. \& Lemos R.A.A. 2006. Doenças do Sistema Nervoso de Bovinos no Brasil. Vol.1. Coleção Vallée, São Paulo. $207 p$.

Bassuino D.M., Konradt G., Cruz R.A.S., Silva G.S., Gomes D.C., Pavarini S.P. \& Driemeier D. 2016. Characterization of spinal Cord lesions in cattle and horses with rabies: the importance of correct sampling to the diagnosis. J. Vet. Diagn. Invest. 28(4):455-460.

Bezerra P.S., Ilha M.R.S., Langohr I.M. \& Barros C.S.L. 2000. Intoxicação experimental por monensina em equinos. Pesq. Vet. Bras. 20(3):102-108.

Döbereiner J., Langenegger J., Tokarnia C.H. \& Dutra I.S. 1992. Epizootic botulism of cattle in Brazil. Dtsch. Tierärztl. Wochenschr. 99(5):188190.

Doutre M.P. 1969. Fréquence au Sénégal du botulism animal d'origine hydrique. Revue Élèv. Med. Vet. Pays Trop. 22(1):29-31.

Dutra I.S. 2001. Epidemiologia, quadro clínico e diagnóstico pela soroneutralização em camundongo do botulismo em bovinos no Brasil, 19892000. Tese de Livre-Docência, Faculdade de Odontologia de Araçatuba, Universidade Estadual Paulista. 133p.

Dutra I.S., Weiss H. \& Döbereiner J. 1993. Diagnóstico do botulismo em bovinos pela técnica de microfixação de complemento. Pesq. Vet. Bras. 13(3/4):83-86.

Dutra I.S., Döbereiner J., Rosa I.V., Souza L.A.A. \& Nonato M. 2001. Surtos de botulismo em bovinos no Brasil associados à ingestão de água contaminada. Pesq. Vet. Bras. 21(2):43-48.

Dutra I.S., Döbereiner J. \& Souza A.M. 2005. Botulismo em bovinos alimentados com cama de frango. Pesq. Vet. Bras. 25(2):115-119.

Fernandes C.G. \& Riet-Correa F. 2007. Doenças bacterianas, p.215-224. In: Riet-Correa F., Schild A.L., Lemos R.A.A. \& Borges J.R.J. (Eds), Doenças de Ruminantes e Equídeos. Vol.1.3a ed. Pallotti, Santa Maria. 716p.

Graça D.L., Alessi A.C., Ecco R. \& Viott A.M. 2010. Patologia do sistema ner- voso, p.580-582. In: Santos R.L. \& Alessi A.C (Eds), Patologia Veterinária. Roca, São Paulo. 892p.

Johnson A.L., McAdams S.C. \& Whitlock R.H. 2010. Type A botulism in horses in the United States: a review of the past ten years (1998-2008). J. Vet. Diagn. Invest. 22:165-173.

Kelly A.P., Jones R.T., Gillick J.C. \& Sims L.D. 1984. Outbreak of botulism in horses. Equine Vet. J. 16(6):519-521.

Kinde H., Bettey R.L., Ardans A., Galey F.D., Daft B.M., Walker R.L., Eklund M.W. \& Byrd J.W. 1991. Clostridium botulinum type-C intoxication associated with consumption of processed alfalfa hay cubes in horses. J. Am. Vet. Med. Assoc. 199(6):742-746.

Kriek N.P.J. \& Odendaal M.W. 2004. Botulism, p.1885-1902. In: Coetzer A.W. \& Tustin R.C. (Eds), Infectious Diseases of Livestock. Vol.3. Oxford University Press, Cape Town. 2159p.

Langenegger J. \& Döbereiner J. 1988. Botulismo enzoótico em búfalos no Maranhão. Pesq. Vet. Bras. 8(1/2):37-42.

Ostrowski S.R., Kubiski S.V., Palmero J., Reilly C.M., Higgins J.K., Cronin S.C., Tawde S.N., Crossley B.M., Yant P., Cazarez R. \& Uzal F.A. 2012. An outbreak of equine botulism type $\mathrm{A}$ associated with feeding grass clippings. J. Vet. Diagn. Invest. 24(3):601-603.

Pabilonia K. 2003. An outbreak of type C botulism in horses in Colorado. Colorado State University. Vet. Diagn. Labs 8(1):7-9.

Ribas A.I., Ferreira R.M.M., Masser R.C., Ciani R.B. \& Dutra I.S. 1994. Detecção de esporos de Clostridium botulinum em costelas de cadáveres decompostos de bovinos. Anais XXIII Congr. Bras. Med. Vet., Olinda, Pernambuco, p.42. (Resumo)

Riet-Correa F., Riet-Correa G. \& Schild A.L. 2002. Importância do exame clínico para o diagnóstico das enfermidades do sistema nervoso em ruminantes e equídeos. Pesq. Vet. Bras. 22(4):161-168.

Ricketts S.W., Greet T.R., Glyn P.J., Ginnett C.D., McAllister E.P., McCaig J., Skinner P.H., Webbon P.M., Frape D.L., Smith G.R. \& Murray L.G. 1984. Thirteen cases of botulism in horses fed big bale silage. Equine Vet. J. 16(6):515-518.

Schoenbaum M.A., Hall S.M., Glock R.D., Grant K., Jenny A.L., Schiefer T.J., Sciglibaglio P. \& Whitlock R.H. 2000. An outbreak of type C botulism in 12 horses and a mule. J. Am. Vet. Med. Assoc. 217(3):365-368.

Seifert H. \& Böhnel H. 1994. Clostridioses, p.89-153. In: Blobel H. \& Schliesser T. (Eds), Handbuch der Bakteriellen Infektionen bei Tieren. Bamd II. Gustav Fischer Verlag, Stuttgart.

Thiongane Y., Leforban Y. \& Doutre M.P. 1984. Le botulisme de type D au Sénégal. Un nouveau foyer d'origine hydrique responsible d'une forte mortalité. Revue Élèv. Med. Vet. Pays Trop. 37(2):151-154.

Tokarnia C.H., Langenegger J., Langenegger C.H. \& Carvalho E.V. 1970. Botulismo em bovinos no Estado do Piauí, Brasil. Pesq. Agropec. Bras., Sér. Vet., 5:465-472.

Valentine B.A. \& McGavin M.D. 2009. Músculo esquelético, p.1006-1010. In: McGavin M.D. \& Donald J.F. (Eds), Bases da Patologia em Veterinária. Elsevier, Rio de Janeiro. 1476p.

Vandevelde M., Higgins R. \& Oevermann A. 2012. Veterinary Neuropathology: essentials of theory and practice. 5th ed. Wiley-Blackwell, Iowa. 200p.

Whitlock R.H. \& McAdams S. 2006. Equine botulism. Clin. Tech. Equine. Pract. 5:37-42.

Wilkins P.A. 2007. Botulism, p.372-376. In: Sellon D.C. \& Long M.T. (Eds), Equine Infectious Diseases. Saunders-Elsevier, St Louis. 653p. 